\title{
Bullying nas escolas: a metodologia dos círculos restaurativos
}

\author{
The bullying in schools: the methodology of restorative circles
}

A la intimidación en las escuelas: un método de círculos restaurativos

\author{
ANDRÉIA MENDES DOS SANTOS* \\ PATRICIA KRIEGER GROSS ${ }^{* *}$ \\ PATRICIA TERESINHA SCHERER***
}

\begin{abstract}
RESUMO - O bullying é uma forma de violência (verbal, física, material, psicológica, moral, sexual ou virtual), de forma intencional e repetida. Esta pesquisa qualitativa foi realizada em quatro escolas de Porto Alegre/RS através de grupos focais com 64 alunos na faixa etária de 9 a 17 anos e entrevistas com 10 profissionais das escolas. O objetivo foi investigar as manifestações do bullying e a efetividade dos círculos restaurativos. Esses são encontros dialógicos entre agressor e vítima, mediados por um coordenador. Visa expressar os motivos subjacentes ao conflito e elaborar acordos. Os resultados evidenciam satisfação em relação aos círculos restaurativos, porém tal prática pode ser paliativa ou punitiva quando o acordo é imposto.
\end{abstract}

Palavras-chave - Bullying. Círculos restaurativos. Violência. Escolas.

\begin{abstract}
Bullying is a form of violence (verbal, physical, material, psychological, moral, sexual, or virtual), intentionally and repeatedly. This qualitative research was conducted in four schools in Porto Alegre/RS through focus groups with 64 students in the age group of 9-17 years and interviews with 10 professional from schools. The objective of this research was to investigate the manifestations of bullying and the effectiveness of restorative circles. These are dialogical encounters between aggressor and victim, mediated by a coordinator. It aims to express the reasons underlying the conflict and elaborate agreements. The results indicate satisfaction with the restorative circles, but this practice may be palliative or punitive when the agreement is imposed.
\end{abstract}

Keywords - Bullying. Circles restorative. Violence. Schools.

RESUMEN - El bullying es una forma de violencia (verbal, física, material, psicológica, moral, sexual o virtual), de forma deliberada y repetidamente. La investigación cualitativa, se realizó en cuatro escuelas en Porto Alegre/RS a través de grupos de enfoque con 64 estudiantes en el grupo de edad de 9-17 años y las entrevistas con 10 escuelas profesionales. El objetivo de la encuesta fue investigar las manifestaciones del bullying y la eficacia de los círculos restaurativos. Estos son los encuentros de dialogo entre el agresor y la víctima, con la mediación de un coordinador. Tiene como objetivo expresar las razones subyacentes del conflicto y hacer acuerdos. Los resultados evidencian la satisfacción en relación a los círculos restaurativos, pero esta práctica puede ser paliativa o punitiva cuando el acuerdo es impuesto.

Palabras clave - Bullying. Círculos restaurativos. Violencia. Escuelas.

\footnotetext{
* Doutora em Serviço Social pela Pontifícia Universidade Católica do Rio Grande do Sul (Porto Alegre, RS, Brasil) e Professora na Pontifícia Universidade Católica do Rio Grande do Sul (Porto Alegre, RS, Brasil).E-mail: <andreiam72@gmail.com>.

** Doutora em Serviço Social pela Universidade de Toronto (Toronto, Canadá) e Professora na Pontifícia Universidade Católica do Rio Grande do Sul (Porto Alegre, RS, Brasil).E-mail: <pkgrossi@pucrs.br>.

*** Doutoranda em Serviço Social na Pontifícia Universidade Católica do Rio Grande do Sul (Porto Alegre, RS, Brasil). E-mail: <alemoa@gmail.com>.
} 


\section{O BULLYING NO CONTEXTO ESCOLAR}

A pesquisa apresentada neste artigo teve como objetivo geral avaliar a efetividade dos círculos restaurativos nas situações identificadas como bullying, em quatro escolas de Porto Alegre/RS (uma estadual, uma privada e duas municipais). Estas escolas tiveram a experiência da realização de círculos restaurativos para a resolução de situações de bullying e outros tipos de violência desenvolvidos pelos estudantes. Foram objetivos específicos da pesquisa: identificar as situações de bullying, compreender como os alunos percebem esse fenômeno e avaliar se os círculos restaurativos contribuem para uma horizontalidade das relações, como no reconhecimento das diferenças dentro do ambiente escolar. Os círculos restaurativos, metodologia originária da justiça restaurativa, têm sido avaliados como um importante procedimento para a intervenção nas situações de bullying nas escolas (GROSSI; SANTOS, 2012).

Bullying é um termo de origem inglesa que, por não existir uma palavra na língua portuguesa capaz de expressar corretamente sua tradução e abrangência, foi adotado no Brasil. As preocupações em relação ao bullying e os relatos de casos destas situações são crescentes. No Estado do Rio Grande do Sul, a Lei 13.474, aprovada por unanimidade na Assembleia Legislativa do Estado e sancionada no dia 29 de junho de 2010 pela então governadora Yeda Crusius, prevê políticas públicas contra o bullying nas escolas privadas e públicas do Estado (RIO GRANDE DO SUL, 2010).

O termo é utilizado para qualificar comportamentos agressivos praticados, neste caso, no âmbito escolar. Refere-se aos atos de violência que ocorrem de forma intencional e repetitiva contra um ou mais estudantes e que não apresentam motivações específicas ou justificáveis. Em outra instância, significa dizer que ocorre quando alguém ou alguns, normalmente com características mais frágeis, são utilizados como meros objetos de diversão, prazer e poder, apenas pelo intuito de maltratar, intimidar, humilhar e amedrontar (FANTE, 2005).

As formas mais frequentes de bullying são: verbal (insultar, ofender, falar mal, colocar apelidos pejorativos); física e material (bater, empurrar, beliscar, roubar, furtar ou destruir pertences da vítima); psicológica e moral (humilhar, excluir, discriminar, chantagear, intimidar, difamar); sexual (abusar, violentar, assediar, insinuar); virtual ou ciberbullying (bullying realizado por meio de ferramentas tecnológicas: celulares, filmadoras, internet, redes sociais, entre outras). Há algum tempo, o fenômeno bullying tem ganhado destaque na mídia que vem relatando situações graves que resultaram em mortes, traumas e suicídios de estudantes. Para Morrison (2006), que alude a diferentes autores quando se refere ao bullying escolar através do abuso sistemático do poder, o desenvolvimento positivo das crianças e adolescentes é inibido, provocando em muitas das vítimas tendências a depressão, estresse pós-traumático e, em casos mais extremos, ideias suicidas, entre outros sofrimentos.

Uma característica comum relacionada ao bullying é ser, muitas vezes, cometido por pessoas conhecidas da vítima. Porém, nestes casos, normalmente o agressor e/ ou agressores são sempre mais poderosos que a vítima e/ou vítimas. Uma consequência desta particularidade é a tendência à perpetuação de um ciclo de violência (PEPLER; CRAIG, 2008), pois, para os mesmos autores, se estabelece "um desequilíbrio de poder entre o agressor e a vítima" (1988, p. 1).

Para Day (1996, p. 44-45), alguns fatores contribuem para o desenvolvimento dos comportamentos agressivos típicos de bullying:

- atitude negativa para com a criança, os pais ou cuidadores;

- a atitude tolerante e permissiva em relação ao comportamento agressivo da criança e/ou adolescente;

- estilo parental autoritário que usa o poder e a violência para controlar a criança ou adolescente;

- tendência natural da criança ou adolescente a ser arrogante.

Alem desses, outros componentes também aparecem na literatura como importantes para a ocorrência de bullying, entre as quais as características pessoais da vítima, do agressor e das próprias testemunhas do bullying que podem interferir na situação, estimulando ou inibindo a sua ocorrência.

Em 2009, o Instituto Brasileiro de Geografia e Estatística (IBGE), realizou uma pesquisa sobre bullying com 618.500 estudantes de escolas particulares e públicas nas capitais brasileiras. Os alunos frequentavam o $9^{\circ}$ ano do ensino fundamental e a maioria encontrava-se na faixa etária de 13 a 15 anos. Os dados mostraram que quase um terço dos alunos $(30,8 \%)$ respondeu ter sofrido bullying alguma vez. Também, nesse estudo, a maior ocorrência de bullying foi verificada entre os alunos de escolas privadas (35,9\%) se comparado os de escolas públicas $(29,5 \%)$ (IBGE, 2010). Outras importantes revelações feitas pelo IBGE: o bullying é mais frequente entre os estudantes do sexo masculino e, em relação às cidades com mais frequência de casos de bullying, aparecem Vitória, Porto Alegre, João Pessoa, São Paulo, Campo Grande e Goiânia.

A crescente exposição da problemática do bullying pela mídia e a exploração desse fenômeno na literatura profissional têm reforçado a consciência sobre este problema. Cabe ressaltar que bullying não ocorre somente no âmbito escolar, (ALMEIDA; SILVA; CAMPOS, 2008), porém preocupações sobre o bullying estão surgindo 
especialmente neste sistema, pois a comunidade escolar vem reconhecendo a importância de intervenção neste problema social generalizado, que provoca graves danos nas relações sociais, independentemente da cultura ou estrato social dos envolvidos (SILVA, 2010). Dessa forma, investir na prevenção e na intervenção aos casos de bullying na escola (e consequentemente na infância e juventude), além de significar interromper essa expressão de violência, constitui-se em importante estratégia para que o bullying que ocorre em outros cenários também seja controlado (GROSSI; SANTOS, 2012).

\section{A JUSTIÇA RESTAURATIVA COMO UMA ABORDAGEM PARA RESOLUÇÃO DE CONFLITOS}

Os processos de justiça podem ser considerados "restaurativos" somente se expressarem os principais valores restaurativos, tais como: respeito, honestidade, humildade, cuidados mútuos, responsabilidade e verdade. Os valores da justiça restaurativa são aqueles essenciais aos relacionamentos saudáveis, equitativos e justos. Devese enfatizar que processo e valores são inseparáveis na justiça restaurativa, pois são os valores que determinam o processo, e o processo é o que torna visíveis os valores. Se a justiça restaurativa privilegia os valores de respeito e honestidade, por exemplo, é de crucial importância que as práticas adotadas num encontro restaurativo exibam respeito por todas as partes e propiciem amplas oportunidades para todos os presentes falarem suas verdades livremente. Por outro lado, conquanto estes valores sejam honrados, há espaço para vários processos e flexibilidade de práticas. (MARSHALL; BOYACK; BOWEN, 2005, p. 270).

No Brasil, a justiça restaurativa teve seus primeiros passos em 2002, em diferentes estados: Brasília, São Paulo - na cidade de São Caetano do Sul - e no Rio Grande do Sul, especificamente em Porto Alegre, através da $3^{\text {a }}$ Vara Regional da Infância e Juventude. É uma "abordagem colaborativa e pacificadora para resolução de conflitos e pode ser empregada em uma variedade de situações (familiar, escolar, profissional, sistema judicial, etc." (MARSHALL; BOYACK; BOWEN, 2005, p. 270).

A justiça restaurativa surgiu do intuito de que as partes envolvidas no conflito consigam superar a situação através do entendimento do fato ocorrido, na visão de cada uma das partes: o que sentiu no momento do ato, o que levou à realização do ato, o que tem passado após o ato, dentre outros questionamentos. Marshall, Boyack e Bowen (2005) salientam que, para alcançar seus objetivos, a justiça restaurativa, utiliza o diálogo entre a vítima e o agressor, conferências de grupo, de comunidade e familiares, círculos de sentenças, painéis comunitários, entre outros recursos. Esses encontros dialógicos chamamse os círculos restaurativos. A abordagem do círculo restaurativo tem foco nas necessidades determinantes e emergentes do conflito, de forma a aproximar e corresponsabilizar todos os participantes com um plano de ações que visa a restaurar laços sociais, compensar danos e gerar compromisso de comportamentos futuros mais harmônicos (BRANCHER, 2008).

Em especial, os círculos restaurativos apresentam-se como uma forma de resolução não violenta de conflitos. A seguir apresentam-se algumas considerações em relação à operacionalização dos círculos restaurativos no ambiente escolar.

\section{A METOdologia dos CÍRCULOS RESTAURATIVOS}

Os círculos restaurativos são espaços nos quais as pessoas chegam de livre e espontânea vontade, podendo ser propostos partir de uma das partes envolvidas: as testemunhas, o agressor ou a vítima. O círculo ocorrerá com a presença do agressor e/ou da vítima e das pessoas afetadas pela situação, porém não há a obrigatoriedade da participação de pessoas que - apesar de envolvidas - não estejam à vontade para conversar em relação ao fato ocorrido. Dos círculos também podem participar familiares, amigos e as comunidades. São encontros orientados por um coordenador, seguindo um roteiro, o que proporciona um espaço seguro e protegido para as pessoas abordarem o conflito, falarem e serem ouvidas com respeito, esclarecendo dúvidas e buscando construir soluções para o futuro, que no caso dos círculos, são os chamados acordos (BRANCHER, 2008).

Os círculos restaurativos ocorrem a partir da realização de três etapas - pré-círculo, círculo e pós-círculo -, sendo que a não realização das três etapas não impede que se reconheça a implantação da proposta. Algumas vezes, pela especificidade do tipo de conflito que ocorre nas escolas ou pela impossibilidade da participação de uma das partes, esse processo ocorre de forma incompleta. Porém, para que possa ser implantada a metodologia dos círculos restaurativos, é necessária à ocorrência do précírculo, que ocorre após a solicitação de uma das partes e da aceitação da outra envolvida. Após a aceitação de ambas as partes, são explicados os processos do círculo restaurativo, ou seja, o pré-círculo. Conforme Brancher (2008, p. 37), o coordenador do círculo deverá:

[...] explicar o que é justiça restaurativa; motivo do círculo - resumo do fato; o que é; como funciona; quem participará; procedimentos e expectativas com relação aos participantes; condições oferecidas para a participação; como se desenvolverá o encontro; o que poderá resultar dos procedimentos; possíveis 
benefícios para os participantes; marcar data, horário e local para realização do encontro; conferir com o autor e o receptor o resumo do fato; prestar esclarecimentos sobre o termo de consentimento; colher a assinatura, disponibilizar uma via do termo para o convidado.

Após o pré-círculo é agendado o círculo restaurativo, onde vítima, agressor, familiares e comunidade sentam-se em círculo, para que se vejam como iguais, para facilitar o diálogo e possibilitar um espaço sem hierarquização por qualquer uma das partes, inclusive do coordenador. Neste momento, o agressor e a vítima irão falar e ouvir sobre seus sentimentos antes, durante e após o conflito. Familiares e comunidade também poderão expressar os sentimentos acerca do que vivenciaram. No momento final serão realizados acordos. A formulação do acordo tem por base as necessidades não atendidas de cada participante, conforme tenham sido identificadas ao longo das etapas (BRANCHER, 2008, p. 38). Para o autor, o acordo consiste em um plano de ações positivas. São estabelecidos compromissos que devem ser concretos, com prazos definidos e identificação dos responsáveis pela ação. $\mathrm{O}$ acordo é formalizado mediante o preenchimento de documento específico e assinado por todos. A última etapa, o pós-círculo, tem o caráter de avaliar se o acordo foi efetivado e se houve a superação do conflito, neste caso o bullying. O pós-circulo será, então, o momento em que se retoma o que ocorreu após o circulo restaurativo para cada parte envolvida. Retoma-se também o acordo, se foi ou não cumprindo.

Os círculos restaurativos não se restringem aos conflitos entre estudantes nas escolas, mas atuam também em relação a outros conflitos típicos da escola, como, por exemplo, entre estudantes e professores. Parte-se do pressuposto de que muitos comportamentos apresentados pelos estudantes na escola são reproduções de suas vivências nas comunidades onde moram, nas famílias e na sociedade, necessitando de intervenções mais amplas. A escola é reprodutora e também produtora de aprendizagens, comportamentos, sentimentos e experiências da sociedade que engloba a comunidade escolar. As experiências de círculos restaurativos terão suas replicações nesses cenários em que o grupo interage, pois a partir de uma lógica de diálogo os sujeitos poderão problematizar e superar as dificuldades que se expressam em relações conflituosas com consequências aos sujeitos e ao ambiente no qual o bullying foi gerado.

\section{METOdOLOGIA}

A pesquisa é uma especial ferramenta, pois a realidade não se desvenda na superfície. A pesquisa, de abordagem qualitativa, intitulada "Identificando e enfrentando o bullying nas escolas públicas e privadas de Porto Alegre através dos círculos restaurativos" foi contemplada no Edital PBIC/CNPq 2008-2009. Participaram do processo quatro escolas de Porto Alegre, sendo uma estadual, uma privada e duas da rede municipal de ensino. Foram realizados cinco grupos focais totalizando 64 alunos com idades entre 9 e 17 anos. Na escola privada, o grupo focal foi realizado com a participação de 12 alunos (6 meninas e 6 meninos, de 9 a 10 anos). Na escola estadual, o grupo focal foi realizado com 14 alunos ( 7 meninas e 7 meninos, de 11 a 13 anos). Em uma escola municipal, foi realizado um grupo focal com 14 alunos ( 7 meninos e 7 meninas, de 11 a 14 anos), na outra escola municipal foram realizados dois grupos focais, um com 13 alunos ( 8 meninos e 5 meninas, com idades entre 15 a 17 anos) e o outro com 11 alunos ( 6 meninas e 5 meninos, entre 9 a 14 anos). Foram realizadas dez entrevistas semiestruturadas com profissionais das escolas. Conforme Minayo (1998), a entrevista é destinada a construir informações pertinentes para um objeto de pesquisa e abordagem pelo entrevistador, de temas igualmente pertinentes, tendo em vista este objetivo.

$\mathrm{Na}$ presente pesquisa, as entrevistas com os professores e coordenadores pedagógicos das escolas visavam compreender suas experiências sociais enquanto participantes dos círculos restaurativos (como coordenador ou envolvido no conflito). Junto aos alunos, foi utilizada a técnica de grupo focal, com o objetivo obter dados a partir de reuniões com um grupo de pessoas, que representam o objeto de estudo, buscando enfatizar a compreensão do fenômeno estudado, do ponto de vista do grupo. Consiste na interação entre os participantes e o pesquisador, objetivando colher dados a partir da discussão focada em tópicos diretivos e focais, por isso chamada de grupo focal (BAUER; GASKELL, 2002). Nesta pesquisa, o grupo focal permitiu compreender a percepção dos estudantes sobre bullying e sobre os círculos restaurativos.

As entrevistas e grupos focais foram gravados e os dados transcritos e também submetidos à análise de conteúdo conforme Bardin (1977). A realização da pesquisa teve aprovação da Comissão Científica e do Comitê de Ética da Universidade (Processo 09/04660), com autorização das secretarias de Educação: Municipal de Porto Alegre e Estadual/RS, assim como também das escolas participantes.

Para a análise do corpus da pesquisa, foram elencadas as seguintes categorias temáticas: (a) compreensão do bullying; (b) motivos relacionados à ocorrência de bullying; (c) efetividade dos círculos restaurativos como estratégia de resolução não violenta de conflitos. 


\section{Resultados e Discussão}

Nas escolas, através dos grupos focais, observou-se em relação à categoria temática compreensão do bullying que os alunos relacionam a palavra bullying com violência e esta se manifesta através das brigas, principalmente agressões físicas ou na forma de ameaças. Através das falas destes, identificou-se a falta de tolerância entre os colegas e que a agressão física é utilizada como uma forma de penalização e intimidação entre os jovens. Estes justificam as brigas quando não concordam com a atitude do colega.

Os estudantes associam o bullying com ameaças e apelidos relacionados à condição física, constituição corporal, orientação sexual e características étnico-raciais, entre outras. Neste contexto, o bullying se manifesta através dos seguintes apelidos, entre outros: "bicha" (A3); "magrela" (A5); "negro" (A2), "baleia" (A4); "rolha de poço" (A22).

Segundo a fala dos estudantes, os apelidos são um tipo de violência psicológica que agride e fere os sentimentos. Dessa forma, pode-se avaliar que os jovens consideram a violência uma questão muito maior que as agressões físicas. Além disso, no transcorrer dos grupos focais, observou-se que, para os alunos, adjetivos de cunho racista e homofóbico direcionados aos colegas são depreciativos e têm a intenção de ofender e ridicularizar.

Ainda sobre o entendimento dos estudantes sobre violência e bullying, observou-se que os alunos também relacionam violência com brigas, com puxões de cabelo, "rasteiras", ameaças, socos, beliscões, arranhões, mordidas, entre outras ações. Um aspecto que merece destaque é que, segundo os alunos, muitas vezes as brigas ocorrem fora da escola, na rua, e acabam chegando até o cenário escolar. Lopes Neto e Saavedra (2004) definem a violência nas escolas como sendo um problema social grave e complexo e, provavelmente, o tipo mais frequente e visível da violência juvenil. Os autores complementam:

O termo violência escolar diz respeito a todos os comportamentos agressivos e antissociais, incluindo os conflitos interpessoais, danos ao patrimônio, atos criminosos, etc. Muitas dessas situações dependem de fatores externos, cujas intervenções podem estar além da competência e capacidade das entidades de ensino e de seus funcionários. Porém, para um sem número delas, a solução possível pode ser obtida no próprio ambiente escolar (LOPES NETO; SAAVEDRA, 2004, p. 19).

Em relação aos motivos relacionados à ocorrência de bullying, situação que tem preocupado a comunidade escolar, observa-se que este resulta da interação entre o desenvolvimento individual e o contexto social, como a família, a escola e a comunidade. A escola reproduz a sociedade e consequentemente também a violência enraizada no tecido social, com isso deixando de ser um ambiente seguro e locus de proteção. Isso não significa que a escola seja apenas um receptáculo da sociedade, pois aquela está inserida nessa, e assim também é (re) produtora de comportamentos que terão reflexo na sociedade. Esse dado se revelou importante quando os alunos trouxeram para o grupo focal a realidade de suas vidas. Segundo a fala de um estudante, muitas atitudes na escola são reflexos do cotidiano destes estudantes em casa, na família, ou na comunidade:

\begin{abstract}
Só que eu acho que esse tipo de coisa assim, a maioria das vezes não é... da escola, é... vem de casa, da família, do exemplo dos pais. Eu acho que isso aí vem daí e dos vizinhos também. Porque, assim, tu mora num lugar assim, difícil, tipo eu que moro numa vila. Isso é o principal, eu acho. E daí assim vai formando todos nós. E daí assim eu acho difícil a gente se concentrar em casa e na escola. Porque na escola é um barulho, em casa já é outro. Só que daí na escola, tipo assim, às vezes vai alunos irritados por causa dos pais, a gente fala alguma coisa e eles te tiram, eles falam besteira aí começa a discussão. Daí o problema dos pais eles trazem para escola, do vizinho, eles trazem pra escola, daí eu acho assim que tá acontecendo (A2).
\end{abstract}

Nessa fala percebe-se que as realidades vivenciadas pelos alunos na escola estão diretamente relacionadas com a sua realidade na família. Muitos reproduzem na escola comportamentos vivenciados na família ou, ainda, trazem para escola carências afetivas, falta de diálogo, de demonstração de carinho e respeito, que desencadeiam em falta de paciência e brigas. Foram constatadas situações de violência além da escola, na família e na comunidade. Os resultados da pesquisa apontam para a dificuldade na convivência com as diferenças entre os alunos nas escolas, especialmente.

Alunos em situação de vulnerabilidade social e emocional estão predispostos a se envolverem em situações de conflitos na escola, pois, segundo Fante (2005), a escola é um lugar do exercício de conflitos e, por isso, é comum que ocorram desentendimentos. Os estudantes trazem nas suas falas o entendimento de que "violência gera mais violência". Isso é exemplificado quando levantam o tom de voz, gritam, falam alguma coisa que ofende o colega e o "ofendido" se defende reproduzindo as mesmas atitudes dos colegas, ou seja, responde com gritos, socos, empurrões e agressões verbais. - "Porque violência gera mais violência" (A4). "Porque tem gente revoltada com a vida" (A1).

O convívio num ambiente de ansiedade, medo e agressividade, afeta os processos de desenvolvimento 
e aprendizagem; gera e incentiva comportamentos agressivos e/ou depressivos, bem como de vingança; provoca reações psicossomáticas, adoecimento dos envolvidos; aumenta os riscos para comportamentos delinquentes, violentos e de abuso de drogas no futuro (SANTOS; GROSSI, 2008, p. 299).

As relações de poder também são destacadas pelos alunos nos grupos focais. Os alunos evidenciam que, muitas vezes, utilizam a violência para defender uma posição, para obter um lugar de destaque na sala de aula e na escola como um todo. O bullying está caracterizado pela discriminação da diferença, pela expressão de supremacia do poder sobre o outro e pela falta de respeito e solidariedade para com o próximo. Tais questões e diferenças podem perpassar por questões de gênero, idade, raça/etnia, classe social, deficiência física e/ou intelectual, orientação sexual, peso, entre outras. O bullying pode ser considerado uma cadeia de comportamentos agressivos (ou não) e de preconceitos no ambiente escolar.

Outro dado revelado foi que muitos alunos trazem para a escola objetos que se tornam armas e são utilizados normalmente para intimidação. Essas situações de intimidação envolvendo armas, em geral, são percebidas pelos professores. Os estudantes argumentaram que tal situação não é frequente no ambiente escolar. Apesar da ocasionalidade, esse fator é importante, pois demonstra falta de respeito, de limites, além de elevada intolerância à frustração, entre outras causas. Também existem situações em que alunos levam facas para se defender de outros alunos que praticam bullying contra eles, por não suportarem mais ser alvo de piadas e humilhações.

É possível analisar que nem sempre os alunos tinham clareza do que se tratava o termo bullying. Muitos reproduziam o entendimento captado em um jogo eletrônico sobre a temática, conforme relato do estudante A5: "Bullying é um jogo de play, no jogo ele bate na professora e passa a mão na bunda das gurias", trazendo esta resposta, quando perguntado sobre o entendimento dele do que era isso na escola. Outros estudantes, no mesmo grupo focal, entendem como bullying: desrespeito aos professores, palavrões, agressão a colegas e professores, apelidos, deboches, violência física. Os estudantes comentam que as brigas são frequentes e que, muitas vezes, começam por motivos pequenos, porém, nestes casos os alunos não relacionam ao bullying.

Os alunos consideram que o bullying traz consequências negativas tanto para o autor como para a vítima. Alguns estudantes revelam que, muitas vezes, apenas refletem a violência a que são submetidos para se defender. Outra questão que surgiu foi na relação entre o professor e alunos. Segundo esses: "O professor grita, grita, grita, grita" (A1), o que demonstra descontrole e dificuldade, também neste âmbito, das relações nas escolas.
Em relação à efetividade dos círculos restaurativos como estratégia de resolução não violenta de conflitos, os alunos entendem que os círculos restaurativos se constituem como um espaço para conversar, pensar e refletir sobre atitudes que geraram sentimentos de humilhação, vergonha, raiva, medo, intimidação, agressão física e verbal. Neste espaço, eles conversam e conseguem, na maioria das vezes, estabelecer e buscar novas relações na escola e, em alguns casos, também na família. Muitos alunos referem-se aos círculos como "um lugar que chamam as pessoas para conversar, porque brigaram e buscam o entendimento entre os envolvidos no conflito" (A32), ou seja, um espaço para resolver os conflitos.

Os estudantes consideram positiva a participação nos círculos restaurativos, embora essa opinião seja unânime. Segundo os alunos, os círculos os fazem pensar sobre o fato ocorrido e muitas vezes se arrependem de ter brigado, discutido e escutam os conselhos dos professores nos círculos, além de perceberem, através do diálogo, que são benquistos na escola. Além disso, os círculos contribuem para elevar a autoestima dos estudantes e geram propósitos de mudança e de reflexão.

Para Brancher (2008), no círculo restaurativo o foco está nas necessidades determinantes e emergentes do conflito, de forma a aproximar e corresponsabilizar todos os participantes, gerando assim o compromisso de comportamentos futuros mais harmônicos. Depois de terem participado dos círculos restaurativos, os alunos demonstram mais clareza sobre os prejuízos causados pela violência e pelos apelidos, e alguns apontam alternativas para diminuir os casos de bullying na escola.

Outra percepção importante dos estudantes, após os círculos restaurativos, foi de levarem para suas casas atitudes de diálogo, de respeito e verdade para com os pais. Segundo fala da estudante abaixo, o diálogo com a família também ajudaria a resolver conflitos na escola e em casa. Ah! Eu acho assim, tem que deixar a timidez de lado
e chegar nos pais e explicar toda a situação que ta
acontecendo, que acontece. Falar a verdade mesmo
que ele brigue. Se eu fizer alguma coisa errada, falar
pro meu pai: "Pai, fiz isso errado!", Sei que ele vai
ficar bravo. Ele, bah! "Vou ti bater!", "Não, pai, não
bate porque não adianta o senhor me bater, só vai
piorar!" Explicar toda a situação para ele, que eu acho
que ele é um adulto, já tem cabeça, ele vai pensar no
assunto e talvez ele vá começar a dar um exemplo e
me entender. Eu acho assim, que a partir do momento
que meu pai começar a me entender, eu vou começar
a entender ele, vou entender a professora e aí eu acho
que ele vai ser bom, um entende o outro, sabe? Ao
mesmo tempo dando um bom exemplo e respeitando
as atitudes que os colegas fazem (A43). 
Grande parte dos alunos considera o círculo restaurativo um espaço que contribui para a cultura do entendimento, do diálogo, uma cultura menos punitiva e mais restaurativa, uma cultura onde todos possam buscar o entendimento por meio do diálogo e não por meio da violência.

Apesar de uma avaliação predominantemente positiva, alguns estudantes entendem que os círculos não contribuem para resolução dos conflitos nem dos casos de bullying. Para esses estudantes, os círculos foram medidas paliativas que resolveram a questão por alguns dias ou semanas. Posteriormente, os casos de bullying e violência tornaram a acontecer com os mesmos estudantes que participaram do círculo restaurativo. Esses estudantes alegam que alguns participantes dos círculos não prestam atenção nas combinações, nos acordos feitos nos círculos e não os cumprem. Também trouxeram um sentimento de vingança como pretexto para reincidir de forma violenta.

Os motivos que levam os estudantes a participarem dos círculos restaurativos são os mais diversos. A maioria é convidada a participar do círculo para resolver questões de agressões físicas e verbais, especialmente quando esses episódios ocorrem com frequência, caracterizando, muitas vezes, bullying. Uma das questões levantadas pelos alunos relacionadas à participação nos círculos restaurativos é a reversão da entrega do bilhete para os pais, com queixas relacionadas ao comportamento do estudante. Ou seja, nestas situações, muitas vezes, os envolvidos não têm a prioridade de resolver a situação, mas de evitar uma reação negativa da família frente ao conhecimento do fato.

Com relação aos acordos estabelecidos nos círculos restaurativos, para os alunos, esses pactos são válidos na medida em que podem identificar o motivo que gerou o conflito, porém não devem ser determinados pelos coordenadores dos círculos, muito menos devem ser ampliados para atividades voltadas ao ambiente escolar. Combinações como realizar serviços comunitários através da limpeza da praça em frente à escola ou do pátio da mesma, pintura de muros da escola, entre outros, segundo os estudantes, "não contribuem para resolver os conflitos, pelo contrário, deixam o cara sem motivação e com baixa estima" (A54). Cabe ressaltar que a metodologia dos círculos restaurativos pressupõe que os acordos dos círculos devem ser pactuados entre as partes envolvidas, no limite de significar ao outro a intenção da reversão do conflito e não deve adquirir um caráter punitivo e, inclusive, perpetuar uma exposição que deprecie os envolvidos. $\mathrm{O}$ círculo, para ser restaurativo, deve ser inclusivo.

Quando questionados sobre que ações que poderiam ocorrer para diminuir a violência e sobre o que foi apreendido a partir da experiência dos círculos restaurativos, os alunos trazem conceitos relacionados ao entendimento pelo diálogo: "Pra cada amigo nosso que vai brigar, a gente dizer assim: Ô, meu, não briga, resolve a coisa conversando e não sei o quê" (A47). Violência não leva a nada. Essa foi a principal mensagem referida pelos alunos no final dos grupos focais, quando eram convidados a deixar alguma fala, mensagem sobre o que apreenderam com os círculos restaurativos.

Outra técnica utilizada na coleta de informações foram as entrevistas semiestruturadas realizadas junto aos professores. Para esses, geralmente as solicitações para os círculos restaurativos têm ocorrido quando há incidência de situações de agressão verbal e sobretudo física. Para uma professora, os círculos são, na maioria das vezes, solicitados pelos professores, não tendo sido ainda a prática introjetada pelos alunos.

Ocorrem situações de os professores serem convidados a participar do círculo e não aceitarem. Na fala a seguir, a professora exemplifica uma situação onde houve essa negativa da professora e o fato foi polêmico:

Professores se queixam de alunos e quando foi solicitado o círculo a professora não aceitou. Foi bem polêmico, a professora ficou bem revoltada. Então é muito difícil isso, porque os professores acham a ideia interessante, se empolgam, acham que o projeto deve ser implementado, né?! Mas quando eles são confrontados, quando algumas atitudes deles são questionadas, eles se sentem ameaçados, se sentem confrontados, e daí não querem discutir. Aí toda a relação democrática do diálogo é bem assim, dizem uma coisa e fazem outra, então não há coerência dentro da escola. Os alunos são mais abertos (P6).

Percebe-se que os professores reconhecem a escola e a sala de aula como uma particularidade da própria sociedade. Por isso os alunos reproduzem na escola e na sala de aula comportamentos de suas realidades (casa, família, comunidade, entre outros). Nas falas dos professores observa-se que, para esses, os alunos são membros de uma totalidade que tem a sua história particular. Uma dificuldade: parte dos professores e orientadores educacionais referiram que alunos - ou um aluno do grupo - não respeitam a figura do professor, ignorando uma autoridade em sala de aula. Segundo os entrevistados, esta é uma das situações mais difíceis de ser trabalhada e reflete uma realidade de casa: muitos alunos não convivem em casa com uma figura que lhes passe autoridade, normas e regras que devem ser cumpridas. Porém, cabe salientar que isso não implica não residir junto à família; mas muitas vezes, esses papéis não estão bem definidos ou não são bem executados. Como consequência, na escola o aluno expressa essa realidade, desafiando o professor, não realizando as atividades propostas e até o ameaçando e o agredindo física e verbalmente. 
Todos os professores e orientadores educacionais entrevistados já haviam participado de círculo restaurativo com os alunos. Destes, dois professores relataram que participaram não na função de coordenador, indicando a presença de conflitos entre professores e alunos. Um dos professores solicitou o círculo restaurativo com uma aluna, pois, segundo relato, a aluna não o respeitava, o agredia verbalmente com frequência e fazia ameaças.

Para os professores, os círculos entre colegas são solicitados em decorrência de diversas situações de bullying e de violência. As mais comuns são: apelidos, discriminação racial e por classe social, agressões verbais e físicas:

É de brigas, assim, violência física, que a gente leva mais em conta. Porque a verbal até tem muito e também é violência!! [...]. Só assim, soco é a linguagem deles, que agridem bastante os colegas. Essas coisas assim e de drogas?! (P4).

A fala desse professor foi destacada, pois foi uma das únicas declarações em que é abordado o assunto de drogas. Apesar da questão da dependência química ser um grave problema social atual, ainda assim não foi uma questão manifestada com frequência por professores e estudantes. Faz-se necessário aqui contextualizar que o foco das entrevistas e grupos focais eram os conflitos que geravam ou eram decorrentes de bullying, não sendo investigada a questão (das drogas) no contexto escolar, porém esse tema deve ser permanentemente abordado pela comunidade escolar.

Assim como entre os estudantes, a questão do bullying desencadeado pela não aceitação das diferenças entre os colegas emergiu nas percepções dos professores sobre os motivos que geram bullying. Segundo os professores, aqueles alunos mais quietinhos, com feição ou comportamentos díspares dos demais colegas, sofrem pela não aceitação de suas "diferenças", por não estarem em concordância com o padrão estabelecido socialmente, principalmente pelos próprios jovens. Também percebem que o bullying ocorre quando certos estudantes são excluídos dos "grupinhos" por diversos motivos. Por exemplo, não são convidados para festas, ficam fora dos trabalhos em grupo.

O bullying é expresso através da intimidação entre os alunos, segundo relato dos professores. Fatores como idade superior ao colega ou maior força física e aparência mais robusta são utilizados como instrumentos de intimidação. Nestes casos, os professores identificam que a disputa normalmente envolve a posse de um objeto como um lanche, um lápis, por exemplo.

Para os professores, nem sempre é fácil identificar a ocorrência de bullying na escola e, muitas vezes, essa é uma dificuldade que advém da falta de denúncia dos envolvidos. Entre os alunos "mais tímidos" (P9), há vergonha de denunciar o bullying, observa-se certo embaraço em sofrer bullying e medo em relação aos autores destas atitudes. Esse conjunto de dificuldades para acusar a existência de bullying gera um sofrimento muito grande para o aluno que não solicita auxílio, em especial se esse for a vítima, mas não somente nestes casos. De modo geral, todas as pessoas que convivem no ambiente em que ocorre bullying acabam sendo prejudicadas em várias instâncias de suas vidas, inclusive com reflexos no rendimento escolar.

Os mais disfarçados são aquelas crianças ou adolescentes mais tímidos demoram mais pra se manifestarem. E que aparentemente são quietos, aparentemente não, eles são quietos. Não trazem nenhuma preocupação pro professor. Crianças mais quietas enfim que não incomodam, não perturbam então se demora mais pra perceber, também não apresentam queixas, esses pra mim são os casos mais difíceis (P8)

Também ganhou destaque nas entrevistas o cyberbullying, situação onde o bullying é praticado na internet, especialmente em sites de relacionamentos. Segundo os professores, esta situação acontece seguidamente e mais entre as meninas. Estudos realizados sobre bullying por Simmons (2004), Guareschi (2008) e Rolim (2010), entre outros, apontam haver diferenças entre o tipo de bullying e gênero. Para Simmons (2004) o bullying praticado por meninos é, na maioria das vezes, mais fácil de ser identificado, enquanto entre as meninas ocorre uma presença mais significativa de "fofocas" e intenções mais pejorativas em relação à colega.

Os professores salientam que percebem os círculos restaurativos como uma estratégia positiva de resolução de conflitos, inclusive nos casos de bullying, pois através dos círculos é possibilitado o diálogo entre eles e os alunos e a reflexão sobre o fato ocorrido. Como resultados destacam a melhoria do processo de aprendizagem e do desempenho dos alunos. Neste sentido, os resultados da pesquisa, no que se refere à percepção dos professores em relação aos círculos restaurativos, apontam para a efetividade dos círculos restaurativos como forma de resolução não violenta de conflitos. A maioria dos professores reconhece no círculo um espaço para o diálogo e entendimento nas situações desencadeadas por bullying e por violência.

Sobre a questão da violência dentro das escolas e suas formas de enfrentamento, houve divergência entre as escolas. A escola particular mostrou uma posição muito definida com relação às agressões: não admite e, quando ocorre, há punições. Segundo a orientadora edu- 
cacional, as agressões não são toleradas dentro do ambiente escolar, e a escola possui um sistema de segurança que, segundo ela, facilmente identifica situações de agressão entre os alunos. Quando ocorre, os alunos são punidos. Nessa escola, no caso de haver agressões físicas, não haveria a possibilidade de agendamento de círculo restaurativo no intuito de solucionar o conflito. Apesar de não ser informado como o caso seria encaminhado, a orientadora declara que a escola não tolera agressões:

Raramente acontece [em relação a agressão física]. Porque a escola tem como um dos critérios realmente limite zero para a questão das agressões. Dentro da escola, a escola realmente não tolera, tem isso muito definido. Agressão física pra escola é considerada falta muito grave. E agressão verbal, quando ocorre, como é um sistema de segurança muito amplo dentro da escola, é percebido rapidamente. Na sala de aula pelo próprio professor, no pátio, em geral agressões no pátio, de brigas, são facilmente identificadas. A não ser que aconteça muito escondido no banheiro, mas a maioria das coisas rapidamente se percebe $(\mathrm{P} 2)$.

Já nas escolas públicas (estadual e municipal), os professores assumem que agressões físicas e verbais existem dentro da escola, mas há empenho para eliminar este tipo de comportamento. Diferentemente da escola privada, nas escolas que participaram da pesquisa, pertencentes à rede pública de ensino, a forma de enfrentamento às situações de brigas e agressões é a proposição do circulo restaurativo.

Os professores, quando perguntados sobre quais ações as escolas poderiam implementar ou continuar desenvolvendo para o enfrentamento do bullying, responderam que as escolas necessitam de ações pontuais e a longo prazo. Esses mencionam que a cultura da não violência, de incentivar a participação dos pais na escola, é um investimento que terá resultados em longo prazo e salientam a importância destas ações para o futuro da escola, dos estudantes e também para a formação de cidadãos. Questões atuais como bullying, preconceito, discriminação e violência foram elencadas pelo grupo docente para fazerem parte das discussões da escola juntamente com os conteúdos pedagógicos trabalhados com os alunos.

Por fim, outro dado relevante apontado pela pesquisa foi o fato de ainda as escolas contarem com poucos funcionários capacitados para trabalhar as questões relacionadas às temáticas elencadas. A pesquisa demonstra que o bullying e a violência estão presentes nas escolas e que estas experiências são prejudiciais a todos os envolvidos. A experiência dos círculos restaurativos como uma estratégia de resolução de conflitos de forma não violenta pode colaborar para a melhoria do ambiente na escola, na família, na comunidade e na sociedade. Princípios que visam ao diálogo, ao respeito e à aceitação do outro são essenciais para a convivência social e o desenvolvimento humano. Se desenvolvidos na escola, entre outros meios através dos círculos restaurativos quando da ocorrência de conflitos, estarão corroborando a construção de uma sociedade melhor, conforme fala do professor: "Eu espero que os círculos restaurativos venham restituindo o conceito de que a sociedade não modifica as pessoas, tampouco a escola, mas a sociedade não se modifica sem a escola" (P1).

\section{CONSIDERAÇÕES FINAIS}

Estudar o bullying escolar implica tornar visíveis as múltiplas expressões de um fenômeno que, ao longo da história, eram percebidas como típicas de uma "brincadeira de mau gosto". Os dados apresentados reafirmam que o bullying traz consequências sociais e psicológicas nos indivíduos envolvidos nessas situações. Os círculos restaurativos como estratégia de resolução não violenta de conflitos em situações de bullying têm obtido resultados positivos ao dar voz à comunidade escolar.

O bullying não é um fenômeno isolado, e sim uma reprodução do meio social em que estudantes, professores e familiares estão inseridos. Assim, um grande desafio nas escolas é o mesmo encontrado na comunidade em geral: o enfrentamento de conflitos. O caminho é longo, mas os primeiros passos desta jornada foram dados. A pesquisa teve a intenção de contribuir com a construção do conhecimento apresentando a experiência de escolas que utilizaram os círculos restaurativos, uma metodologia recente e uma abordagem a ser avaliada para ser utilizada nas escolas.

Neste artigo, diversas áreas envolvidas com a temática - tais como: educação, serviço social, psicologia, entre outras - são convidadas a refletir, a partir dos resultados da pesquisa, sobre práticas e ações necessárias para a intervenção nos casos de bullying e violência nas escolas. Os círculos restaurativos, metodologia descrita, aponta como forma de resolução não violenta para esses casos. A experiência das cinco escolas assinala uma possibilidade que carece ainda de muita qualificação, de ajustamento ao cenário escolar, com o reconhecimento das particularidades da infância e da juventude. Neste contexto, conclui-se que os círculos restaurativos têm se apresentado como uma ferramenta facilitadora do diálogo, da valorização e do respeito pelo outro e, nas escolas pesquisadas, desponta como uma estratégia positiva para o enfrentamento aos casos de bullying quando respeitados todos os princípios nele inerentes. 


\section{REFERÊNCIAS}

ALMEIDA, Kathanne Lopes; SILVA, Annamaria Cavalcante; CAMPOS, Jocileide Sales. Importância da identificação precoce da ocorrência do bullying: uma revisão de literatura. Revista Pediatria, Fortaleza, v. 9, n. 1, p. 8-16, 2008.

BARDIN, Laurence. Análise de conteúdo. Lisboa: Edições 70, 1977.

BAUER, Martin, W; GASKELL, George. Pesquisa qualitativa com texto, imagem e som: um manual prático. Petrópolis: Vozes, 2002.

BRANCHER, Leoberto. Práticas restaurativas: manual de práticas restaurativas. Porto Alegre, 2008. (apostila)

DAY, Nancy. Violence in schools: learning in fear. Berkeley Heights, NJ: Enslow, 1996.

DEMO, Pedro. Metodologia científica em ciências sociais. 3. ed. São Paulo: Atlas, 1995.

FANTE, Cleo. Fenômeno bullying: como prevenir a violência nas escolas e educar para a paz. 2. ed. rev. Campinas: Verus, 2005.

GROSSI, Patrícia Krieger; SANTOS, Andreia Mendes dos. Bullying in Brazilian schools and restorative practices. Canadian Journal of Education, v. 35, p. 120-136, 2012.

GUARESCHI, Pedrinho; SILVA, Michele. Bullying: mais sério do que se imagina. Porto Alegre: EDIPUCRS, 2008.

IBGE - Instituto Brasileiro de Geografia e Estatística. Disponível em: <http://www.ibge.gov.br/home/presidencia/ noticias/noticia_visualiza.php?id_noticia $=1525>$. Acesso em: 20 ago. 2010.

LOPES NETO, Aramis Antonio; SAAVEDRA, Lucia Helena. Diga não para o bullying. Rio de Janeiro: ABRAPI, 2004.

MARSHALL, Chris; BOYACK, Jim; BOWEN, Hellen. Como a justiça restaurativa assegura a boa prática: uma abordagem baseada em valores. In: SLAKMON, C.; DE VITTO, R.; PINTO, R. Gomes. Justiça restaurativa. Brasília: Ministério da Justiça, PNUD, 2005.

MINAYO, Maria Cecília de Souza. O desafio do conhecimento: pesquisa qualitativa em saúde. 5. ed. São Paulo: Hucitec; Rio de Janeiro: Abrasco, 1998.
MORRISON, Brenda. Bullying escolar e justiça restaurativa: compreensão teórica do papel do respeito, orgulho e vergonha. The Society for the Psychological Study of Social Issues. 2006. Disponível em: <http://snowbirdbooks.com/ images/downloads\%20gratuitos/liv_justica_restaurativa. pdf\#page=19>. Acesso em: 21 ago. 2010.

PEPLER, Debra; CRAIG, Wendy. Promuovere le relazioni ed eliminare la violenza - il modello PREVNet in Canada (Promoting Relationships and Eliminating Violence - The PREVNet Model in Canada). Età evolutiva 90, 97-105, 2008

PEPLER, Debra;\& CRAIG, Wendy. Making a Difference in Bullying. Disponível em: http://psycserver.psyc.queensu.ca/ craigw/Craig_Pepler_2000_REPORT_Making_a_Difference in Bullying.pdf 1988. Acesso em 25 out. 2013.

RIO GRANDE DO SUL. Lei 13.474, de 28 de junho de 2010. Dispõe sobre o combate da prática de "bullying" por instituições de ensino e de educação infantil, públicas ou privadas, com ou sem fins lucrativos. Diário Oficial do Estado do Rio Grande do Sul, n. 121, 29 jun. 2010. Disponível em: <http://www.al.rs. gov.br/Legis/Arquivos/13.474.pdf>. Acesso em: jul. 2010.

ROLIM, Marcos. Bullying: o pesadelo da escola. Porto Alegre: Dom Quixote, 2010.

SANTOS, Andreia Mendes dos; GROSSI, Patricia K. Fenômeno bullying: desvendando esta violência nas escolas públicas de Porto Alegre. Revista Textos \& Contextos, Porto Alegre, v. 7, n. 2, p. 286-301. jul./dez. 2008. Disponível em: $<$ http://revistaseletronicas.pucrs.br/ojs/index.php/fass/article/ viewFile/4827/3633>. Acesso em: 23 jun. 2011.

SANTOS, Andreia Mendes dos; GROSSI, Patricia K. Desvendando o fenômeno bullying: a situação das escolas de Porto Alegre/Brazil. México: Académica Espanõla, 2012. v. 1, p. 130 .

SILVA, Ana Beatriz Barbosa. Bullying, Cartilha 2010 - Projeto justiça nas escolas. Brasília, DF: MEC, 1. ed. 2010.

SIMMONS, Rachel. Garota fora do jogo: a cultura oculta da agressão nas meninas. Rio de Janeiro: Rocco, 2004.

Artigo recebido em agosto 2013.

Aprovado em janeiro 2014 